\title{
Influence of Electron Beam Irradiation and Step-Crosslinking Process on Solvent Penetration and Thermal Properties of Natural Rubber Vulcanizates
}

\author{
M. Madani ${ }^{1}$ and M. M. Badawy ${ }^{2}$ \\ ${ }^{1}$ Radiation Physics Department, National Center for Radiation \\ Research and Technology (NCRRT), Nasr City, Cairo, Egypt. \\ ${ }^{2}$ Physics Department, Faculty of Science, Cairo University, Giza, \\ Egypt.
}

The influence of both electron beam irradiation and step-crosslinking process on the high abrasion furnace (HAF) carbon black loaded natural rubber (NR) vulcanizates are reported. With irradiation, a higher crosslinking density, $v$, thermal conductivity, $\lambda$, glass transition temperature, $T_{g}$, and decreased specific heat capacity, $\mathrm{Cp}$, have been observed for the irradiated materials as compared with the unirradiated ones. Meanwhile, the step-crosslinking process has a slight effect on the crosslinking density, glass transition temperature and thermal properties of these composites. The results of such changes in thermal conductivity are explained with the help of a simple modified model.

\section{Introduction:}

The ability of polymers to act as electrical insulators is the basis for their widespread use in the electrical and electronic fields. However, material designers have sought to combine the fabrication versatility of polymers with many of the electrical properties of metals. There are instances when an increasing conductivity $(\sigma)$ or relative permitivity $\left(\varepsilon^{\prime}\right)$ of a polymer is warranted, such as in applications which require antistatic materials, lowtemperature heaters, electromagnetic radiation shielding, and electric field grading. An extrinsic approach of imparting conductivity to a polymer is through the creation of conducting polymer composite (CPC) materials. CPC materials require a random distribution of conducting filler to be disbursed throughout an insulating polymer and have been the focus of a number of studies on the theoretical aspects of their conductivity [1-3], temperature sensitivity [4], influence of additives on conductivity [5-8], dielectric properties 
[9], switching characteristics [10], influence of irradiation on conductivity [11] and influence of matrix properties [12].

Carbon materials are often added to polymers to obtain composite materials with improved mechanical and electrical properties, but there are few reports on improving thermal conductivity by adding carbon materials [13-15]. The thermal properties of materials are often durability evaluation [16]. Particular attention has been dedicated to polymeric materials [17-19], that are largely used under various hard operation conditions. Modification in heat capacity can explain macroscopic effects as the result of structural changes in the internal energy of materials. In the case of polymers, the increase in oscillation amplitude is accompanied by production of free radicals which are often wards involved in competitive processes, like recombination and oxidation. Hands [20] reported that, the thermal conductivity of black loaded natural rubber composite appreciably depends on the orientation and dispersion of the carbon particles through the rubber matrix. One have therefore considered systematically the effect of step-crosslinking process on thermal conductivity of high abrasion furnace (HAF) black loaded NR samples and the results are reported in this work.

Radiation effects on the polymer properties give information on the molecular structure and transport processes. Thus, the information about the phonon mechanism of energy transfer in the polymers and phase composition of the polymeric materials can be obtained from the changes of thermal conductivity $\lambda$ [21]. Banik et al [22-25], in a series of publications, concerning the influence of electron beam (EB) irradiation on fluorocarbon rubber found a drastic change of mechanical [22], dynamic mechanical [23] electrical properties [24] and thermal stability [25].

The aim of this study was to systematically investigate the effect of both the step-crosslinking process and the electron beam irradiation dose on the thermal properties as well as the solvent (methyle ethyle ketone, MEK) penetration into HAF black loaded NR vulcanizates. Moreover, a simple model proposed by Agari et al [15] to calculate the effective thermal conductivity of the composite was tested as a function of electron beam irradiation dose and step-crosslinking process.

\section{Experimental:}

Materials used and the formulations of different mixes are given in Table (1). NR and all ingredients have been supplied by Engineering and Transport Co., TRENCO, Alexandria, Egypt. Mixing was carried out under 
identical conditions of time, temperature and sequence for all compounds. Using a two-roll mill $170 \mathrm{~mm}$ diameter, working distance $300 \mathrm{~mm}$, speed of slow roll $18 \mathrm{rpm}$, nip gap of about $3 \mathrm{~m}$, gear ratio 1.4 and time of mixing is 30 min. for all samples.

Table 1: The composition of HAF/ NR

\begin{tabular}{|c|c|c|c|c|c|c|c|c|c|}
\hline \multirow{2}{*}{$\begin{array}{c}\text { Extension } \\
\text { During } \\
\text { curing }\end{array}$} & $\begin{array}{c}\text { Ingradients, } \\
\text { phr }\end{array}$ & \multirow[t]{2}{*}{$N R$} & \multirow{2}{*}{$\begin{array}{c}\text { Stearic } \\
\text { Acid }\end{array}$} & \multirow[t]{2}{*}{$\mathrm{ZnO}$} & \multirow[t]{2}{*}{$H A F$} & \multirow{2}{*}{ oil } & \multirow{2}{*}{$P \beta N^{(a)}$} & \multirow[t]{2}{*}{$M P T S^{(b)}$} & \multirow[t]{2}{*}{$S$} \\
\hline & Sample & & & & & & & & \\
\hline \multirow{4}{*}{ 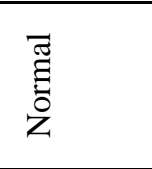 } & $0 \mathrm{HAF}$ & 100 & 2 & 5 & 0 & 10 & 1 & 2 & 2 \\
\hline & $10 \mathrm{HAF}$ & 100 & 2 & 5 & 10 & 10 & 1 & 2 & 2 \\
\hline & $30 \mathrm{HAF}$ & 100 & 2 & 5 & 30 & 10 & 1 & 2 & 2 \\
\hline & $50 \mathrm{HAF}$ & 100 & 2 & 5 & 50 & 10 & 1 & 2 & 2 \\
\hline \multirow{4}{*}{ o $\frac{\overline{0}}{\sqrt[0]{\tilde{d}}}$} & 0HAF/ $30 \%$ & 100 & 2 & 5 & 0 & 10 & 1 & 2 & 2 \\
\hline & $10 \mathrm{HAF} / 30 \%$ & 100 & 2 & 5 & 10 & 10 & 1 & 2 & 2 \\
\hline & $30 \mathrm{HAF} / 30 \%$ & 100 & 2 & 5 & 30 & 10 & 1 & 2 & 2 \\
\hline & $50 \mathrm{HAF} / 30 \%$ & 100 & 2 & 5 & 50 & 10 & 1 & 2 & 2 \\
\hline \multirow{4}{*}{ 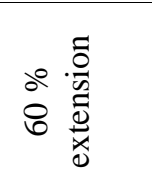 } & 0HAF/ $60 \%$ & 100 & 2 & 5 & 0 & 10 & 1 & 2 & 2 \\
\hline & $10 \mathrm{HAF} / 60 \%$ & 100 & 2 & 5 & 10 & 10 & 1 & 2 & 2 \\
\hline & $30 \mathrm{HAF} / 60 \%$ & 100 & 2 & 5 & 30 & 10 & 1 & 2 & 2 \\
\hline & $50 \mathrm{HAF} / 60 \%$ & 100 & 2 & 5 & 50 & 10 & 1 & 2 & 2 \\
\hline
\end{tabular}

phr, part per hundred part from rubber by weight

One) Phenyl- $\beta$ - napthylamine.

Two) Dibenthiazyl disulfide.

The compounds were sandwiched between protective films (from polyethylene terephthalate, PET) and partially crosslinked by heating it for a time, $\mathrm{t}_{1},\left(3 \mathrm{~min}\right.$.) at the optimum vulcanisation temperature of $150^{\circ} \mathrm{C}$ and at a pressure of $4.5 \mathrm{Mpa}$, between electrically heated plates. The protective films were then removed and the flat sheet was subjected to a different biaxially extension $(0,30$ and $60 \%$ from the initial length) by using a simple constructed equibiaxial stressing frame and then subjected again to further crosslinking for a time, $t_{2},\left(17 \mathrm{~min}\right.$.) at the same temperature. The total time $\left(t_{1}+t_{2}\right)$ was chosen from rheometer curves to give essentially complete thermal curing.

Volume fraction of rubber $\left(V_{r}\right)$ in the vulcanizate was determined using the equilibrium swelling method in MEK at $30^{\circ} \mathrm{C}$ and the following equation [26]: 


$$
V_{r}=\frac{(D-F T) \rho_{r}^{-1}}{(D-F T) \rho_{r}^{-1}+A_{o} \rho_{s}^{-1}}
$$

where $T$ is the weight of the test specimen, $F$ is the weight fraction of the insoluble components in the specimen, $D$ is the deswollen weight of the test specimen, $A_{o}$ is the weight of absorbed solvent (corrected for swelling increment) and $\rho_{r}$ and $\rho_{s}$ are the density of rubber and solvent receptively. The cured sheets of dimension $\left(50 \times 50 \times 2 \mathrm{~mm}^{3}\right)$ were irradiated, by using the facilities of Institut für Oberflächenmodifizierung, IOM, Leipzig, Germany, by an electron beam accelerator, $10 \mathrm{MeV}$ (Electronika- U003, Toriy Co., Moscow), in air over the dose ranges (0- $1500 \mathrm{kGy})$.

The measurements of thermal conductivity of NR composites were recorded by using DSC, Perkin Elmer DSC7, Germany, on the bases of Hakvort and Van Reijen method [27]. The temperature at the upper surface of the disk specimen is not measured directly but it was maintained constant at the melting point of a pure substance (Gallium). For vulcanized NR sample (without HAF black) the calculated thermal conductivity value of $0.15 \mathrm{w} / \mathrm{mK}$ at $35^{\circ} \mathrm{C}$ gives results that are closer to the published data [28, 29]. A further advantage of the DSC method is that the specific heat can be readily determined using a standard specimen from $\mathrm{Al}_{2} \mathrm{O}_{3}$. By knowing specific gravity, the thermal diffusivity, $\alpha$, can be obtained from the relationship $\alpha=\lambda / \rho C p$, where $\lambda=$ thermal conductivity, $\rho=$ specific gravity and $\mathrm{Cp}=$ specific heat at constant pressure.

\section{Results and Discussion:}

\subsection{Polymer- filler interaction}

The extent of polymer- filler interaction is estimated from the swelling experiment and a trial is made to calculate the effect of step-crosslinking process on this interaction using a plot of $V_{r o} / V_{r f}$ versus $C /(1-C)$ according to the following Kraus equation [30, 31].

$$
\frac{V_{r o}}{V_{r f}}=1-\frac{m C}{(1-C)}
$$

where $V_{r f}$ is the volume fraction of rubber in the filled vulcanizate, $V_{r o}$ is the volume fraction of rubber in the unfilled vulcanizate, $C$ is the volume fraction of filler in the vulcanizate and $m$ is the polymer- filler interaction parameter obtained from the slope of the $V_{r o} / V_{r f}$ versus $C / 1-C$ plot. The slope should be positive for reinforcing filler having good polymer- filler interaction, and 
negative for non-reinforcing filler with very weak filler interaction. It is observed from Fig.(1) that, the polymer-filler interaction for samples vulcanized through one step- crosslinking process is high compared with that vulcanized through the two step- crosslinking process (with $30 \%$ and $60 \%$ biaxial extension), the latter having poorer polymer- filler interaction, respectively.

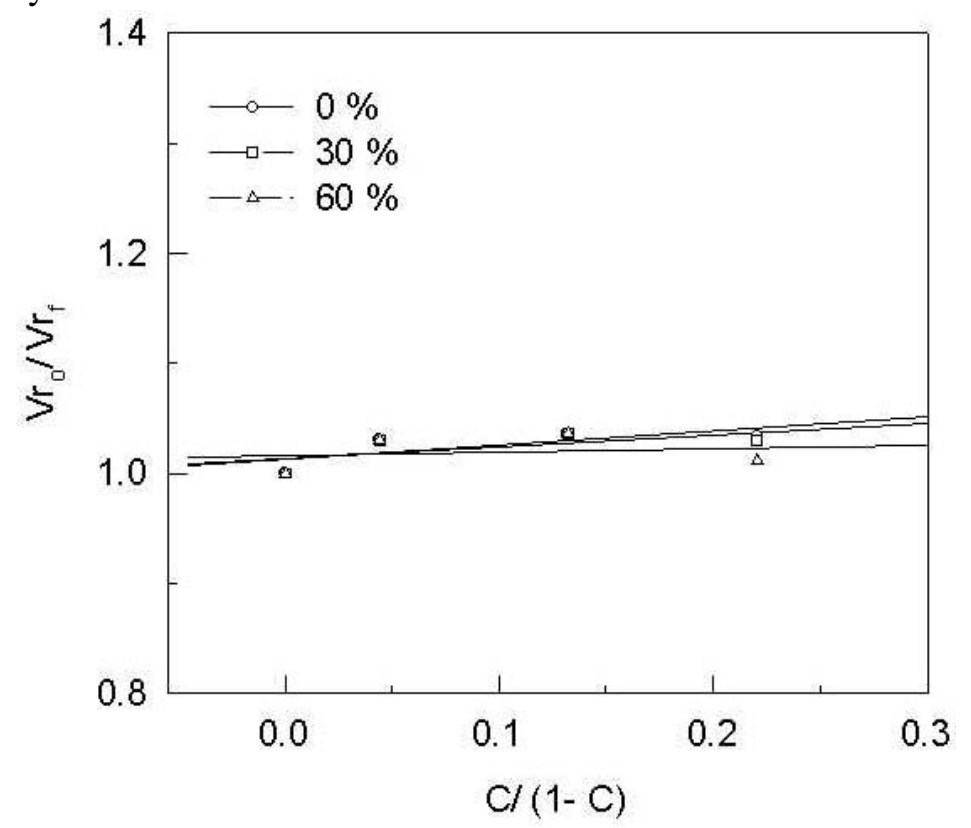

Fig. (1): The relation between $V_{r o} / V_{r f}$ and $C /$ (1-C) for un-irradiated composites.

The variation of maximum amount of solvent uptake with HAF black concentration (phr) for HAF/ NR composites are shown in Fig. (2). It is seen that the maximum uptake value of MEK of all composites shows a similar trend of decreasing with HAF content. The influence of filler content on the properties of reinforced- elastomers has been extensively reported in the literature [32]. It is generally agreed that the decrease in MEK uptake is due to the strong interactions between polymer chains and carbon black particles, and/ or between particles and particles. The values of MEK uptake seem to be independent of the curing condition. This can be explained on the basis of the fact that the swelling measurements can not be taken as a good indicator for rearrangement of $\mathrm{CB}$ particles in the host material as it is a good sensor for crosslink. Fig. (3) shows the MEK uptake variation of the composites with electron beam $(\mathrm{EB})$ irradiation dose at room temperature $\left(30^{\circ} \mathrm{C}\right)$. It is observed 
that MEK uptake decreases with irradiation dose. The decrease in MEK uptake with radiation dose is due to the increase in the formation of a threedimensional network structure. The swelling results suggest that radiation exposure in air causes polymer crosslinking that affect the crosslink density. In order to verify this conclusion, the crosslinking density $\left(v_{p}=\rho_{r} N / M_{c}\right)$ (where $N$ is Avogadro's number) of the composites has been calculated, using the following simplified Flory-Rehner Equation, and reported in Table (2).

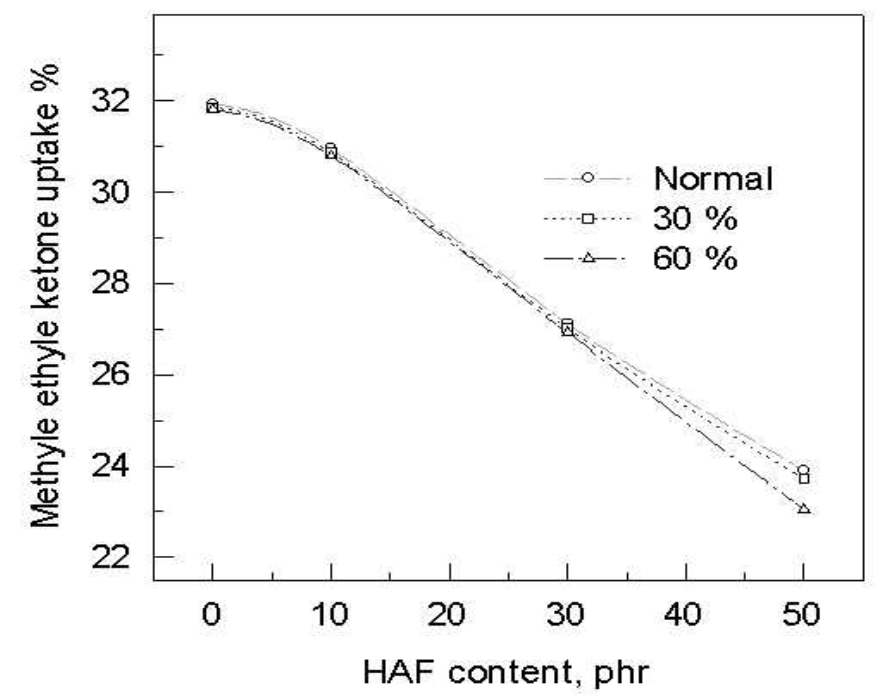

Fig. (2): The variation of solvent uptake with HAF black concentration for all composites.

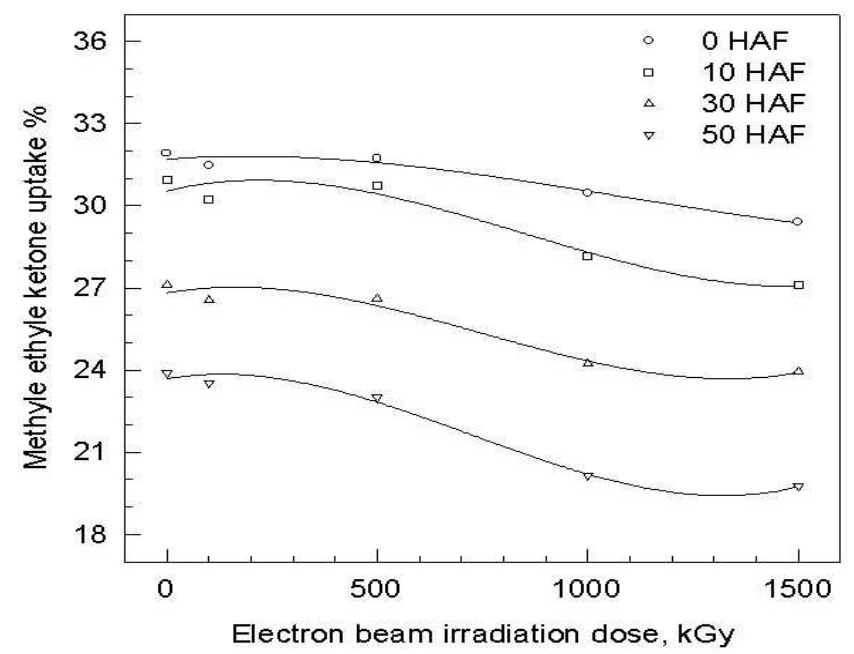

Fig. (3): The variation of maximum amount of solvent uptake with electron beam irradiation dose, for HAF / NR composites. 


$$
M_{c}=-\frac{\rho_{r} V_{s}\left(V_{r}\right)^{1 / 3}}{\ln \left(1-V_{r}\right)+\chi V_{r}^{2}}
$$

where $\rho_{r}$ is the density of the rubber, $M_{c}$ is the average molecular weight crosslinked polymer, $V_{s}$ is the molar volume of the solvent, $V_{r}$ is the volume fraction of elastomer in solvent swollen filled composites and $\chi$ is the solvent interaction parameter, which is given by the equation;

$$
\chi=V_{s} \frac{\left(\delta_{1}-\delta_{2}\right)^{2}}{R T}
$$

where $\delta_{1}$ and $\delta_{2}$ are the cohesive energy density (c.e.d) of solvent and polymer respectively, $V_{s}$ is the molar volume of the solvent and $\mathrm{R}$ is the universal gas constant. $\delta_{2}$ was taken from a previous work for $\mathrm{NR}\left(\approx 38.9 * 10^{3}\left(\mathrm{~J} / \mathrm{m}^{3}\right)^{1 / 2}\right)[33]$, which was calculated using Gee method. Detailed description of the calculation of the crosslinking density was given elsewhere [33,34]. It can be seen from Table (2) that the crosslinking density of the matrix increases with increasing filler content. It is also observed that the results are nearly in line with those of swelling measurements, supporting the formation of network structure on irradiation. Moreover, it is interesting to note that, the sample with higher concentration from $\mathrm{CB}, 50 \mathrm{phr}$, is highly affected by the curing condition. As the elongation during curing increases the degree of crosslinking increases too. It may be pointed out that at higher radiation dose, there is a possibility of chain scission. From the present data, it is appearent that, network formation supercedes the scission of network. Also, if scission predominates at higher doses, the increase in the number of network chains per unit volume can be accounted for by the fact that chain fractures possibly lead to entanglement coupling which then act as crosslinks [22].

Table (2): The calculated crosslinking density per cc at different radiation

\begin{tabular}{|c|c|c|c|c|c|}
\hline \multirow[t]{2}{*}{$\underline{\text { Sample }}$} & \multicolumn{5}{|c|}{$v_{p} \times 10^{-19}$} \\
\hline & 0 kGy & $100 \mathrm{kGy}$ & $500 \mathrm{kGy}$ & $1000 \mathrm{kGy}$ & $1500 \mathrm{kGy}$ \\
\hline 0NR/ $0 \%$ & 178.62 & 182.98 & 180.37 & 193.39 & 205.58 \\
\hline $0 \mathrm{NR} / 30 \%$ & 178.91 & 183.68 & 181.15 & 192.96 & 205.61 \\
\hline $0 \mathrm{NR} / 60 \%$ & 179.09 & 184.39 & 181.19 & 192.75 & 205.26 \\
\hline $10 \mathrm{NR} / 0 \%$ & 179.83 & 187.21 & 181.90 & 210.54 & 224.58 \\
\hline $10 \mathrm{NR} / 30 \%$ & 180.15 & 188.54 & 183.83 & 207.71 & 221.16 \\
\hline $10 \mathrm{NR} / 60 \%$ & 180.34 & 189.94 & 185.53 & 205.86 & 219.01 \\
\hline $30 \mathrm{NR} / 0 \%$ & 215.35 & 222.94 & 222.49 & 257.80 & 262.99 \\
\hline
\end{tabular}
doses. 


\begin{tabular}{l|lllll}
\hline 30NR/ 30\% & 215.59 & 224.17 & 225.07 & 254.39 & 258.40 \\
$30 \mathrm{NR} / 60 \%$ & 215.80 & 218.67 & 226.87 & 252.34 & 254.77 \\
\hline 50NR/ 0\% & 243.67 & 250.16 & 242.16 & 317.18 & 326.09 \\
$50 \mathrm{NR} / 30 \%$ & 246.82 & 254.15 & 248.67 & 284.18 & 300.14 \\
$50 \mathrm{NR} / 60 \%$ & 258.03 & 262.24 & 258.12 & 294.57 & 291.42 \\
\hline
\end{tabular}

\subsection{Composite glass transition temperature}

Saxena et al [35] mentioned that in amorphous polymers there exist some local order which is termed as intermediate range order (IRO). In low temperature region below the glass transition temperature $T_{g}$, the temperature dependant of thermal conductivity is controlled by variation of phonon mean free path. During cooling certain defects are also created in the system, such as bends in chains, gaps between two chains in line, chains of smaller lengths than the others etc., hence below $\mathrm{T}_{\mathrm{g}}$ structure scattering and chain-defect scattering are the main phonon scattering mechanisms. In the former case lattice waves propagate uniformly inside each small domain with dimensions equal to the size of the IRO region and then are scattered by a sudden change of refractive index at the boundary. The dimensions of IRO at $\mathrm{T}_{\mathrm{g}}$ depend mainly on the processing conditions and degree of crosslinking, hence it does not vary with temperature. Therefore the contribution to thermal resistance corresponding to these processes is temperature-independent. The differential scanning calorimeter DSC of a few irradiated samples have been performed. Table (3) presents the glass transition temperature of various irradiated samples.

Table (3): The glass transition temperature $\left(\mathrm{T}_{\mathrm{g}}\right)$ at different radiation doses.

\begin{tabular}{l|llll}
\hline \multirow{2}{*}{ Sample } & \multicolumn{4}{|c}{$\mathbf{T}_{\mathbf{g}}\left({ }^{\mathbf{0}} \mathbf{C}\right)$} \\
\cline { 2 - 5 } & $\mathbf{0} \mathbf{k G y}$ & $\mathbf{5 0 0} \mathbf{~ k G y}$ & $\mathbf{1 0 0 0} \mathbf{~ k G y}$ & $\mathbf{1 5 0 0} \mathbf{k G y}$ \\
\hline $0 \mathrm{NR} / 0 \%$ & -36.0 & -34.7 & -32.9 & -30.7 \\
$0 \mathrm{NR} / 30 \%$ & -36.1 & -34.6 & -33.1 & -30.6 \\
$0 \mathrm{NR} / 60 \%$ & -36.1 & -34.6 & -32.0 & -30.7 \\
\hline $50 \mathrm{NR} / 0 \%$ & -73.5 & -71.2 & -69.5 & -67.5 \\
$50 \mathrm{NR} / 30 \%$ & -73.1 & -71.3 & -69.3 & -67.4 \\
$50 \mathrm{NR} / 60 \%$ & -72.5 & -71.3 & -69.2 & -67.1 \\
\hline
\end{tabular}

As can be observed from Table (3), the glass transition temperature was seemed to be dose dependent, meanwhile it seems to be independent of curing conditions. $\mathrm{T}_{\mathrm{g}}$ of a polymer is a sensitive indicator of crosslinking [22]. A change in the transition temperature of vulcanized rubbers due to electron beam irradiation has been reported [23]. The authors observed shifting of glass transition temperature to lower region with increasing radiation dose, which 
was due to the increase in the extent of crosslinking. Another study in the field of effect of EB irradiation on the transition temperature of aromatic polyslphone has been done by Sasuga et al [36]. They observed a reduction decrease of $T_{g}$ ( $\beta$ - relaxation peak) with increasing radiation dose, which was due to degradation of the sulphone moiety by chain scission.

\subsection{Composite thermal conductivity:}

Morgan and Scovell [37] postulated the existence of one dimensional mode traveling along the chains with long mean free paths and which may be scattered by chain ends, crosslinks or interactions with other molecules. These wave packets are very efficient heat carriers, but the resultant conductivity is low because there are not many of them. Morgan calculated the conductivity from the mean free path using kinetic theory. The effective mean free path depends on the distance traveled within the bulk polymer rather than the distance traveled along the chain. If one assumes a random walk model for a polymer molecule, then the effective mean free path depends on the root mean square distance between scattering centers, which is proportional to the square root of the chain length. It follows from this that the thermal conductivity in a given direction is proportional to the appropriate orthogonal projection of the end- to- end vector.

Generally, carbon black increases thermal conductivity in all elastomers. Fig. (4) shows that, the thermal conductivity of HAF black in NR bladder compound is a non-linear function of the volume fraction of the black at different curing states. When a filled rubber is stretched, during stepcrosslinking process, only the conductivity of the rubber changes according to the rearrangement of filler distribution, while the conductivity of filler itself remains constant. From Fig. 4, one can notice the existence of a shoulder at 30 $\%$ extension for 10 and $30 \mathrm{phr}$ HAF loading. This effect may be due to the rupture of a crosslink removes a scattering center and enable the molecule to assume an entropically more favourable configuration. The net result is an increase in the length of the projection of the end- to- end vector on the axis perpendicular to the stretching direction, and hence, an increase in the conductivity in that direction. Further extension causes the conductivity to decrease. The effect of biaxial extension clearly observed for NR loaded with $50 \mathrm{phr}$ of HAF black, where the thermal conductivity increase by $15 \%$ by increasing the biaxial extension to $60 \%$ during vulcanization process.

Thermal conductivity, like many other physical properties, is an additive function of the volume fraction of the constituents. There are many types of composition systems in which a polymer is filled with particles. In 
those systems, the thermal conductivity of a composite is the highest, in the event that the formed conductive block which all particles are gathered to form and the block of the polymer are arranged in parallel in the case of direction of thermal flux (parallel conduction). While, thermal conductivity is the lowest in the case when those blocks that are arranged in series in the direction of thermal flux (series conduction). Thermal conductivity of composites in parallel and series conduction can be estimated respectively by the following two equations;

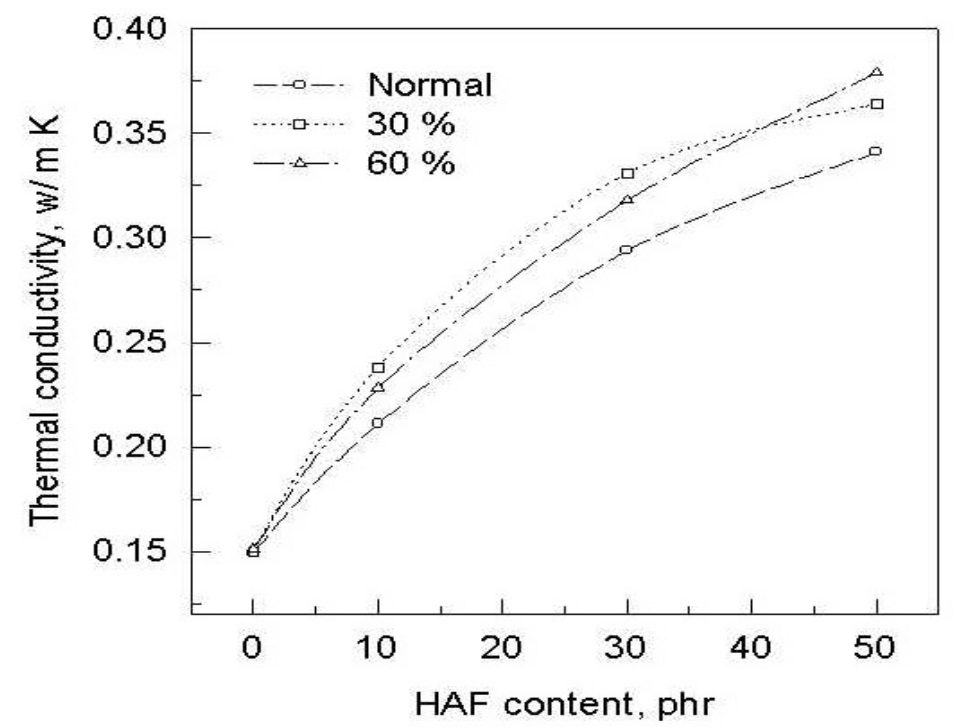

Fig. (4): The thermal conductivity of all composites as a function of HAF content, phr, at different curing states.

Parallel conduction:

$$
\lambda=V \lambda_{2}+\left[(1-V) \lambda_{1}\right]
$$

Series conduction

$$
\frac{1}{\lambda}=\frac{V}{\lambda_{2}}+\frac{(1-V)}{\lambda_{1}}
$$

where $\lambda=$ thermal conductivity of composite, $\lambda_{I}=$ thermal conductivity of polymer, $\lambda_{2}=$ thermal conductivity of filler, and $V=$ volume content of filler. Agari et al [38] assume a generalization of equations (5) and (6) to the following equation (7). Where, if $n=(1)$ or $(-1)$, equation (7) correspond to equation (5) or equation (6) and $\mathrm{n}$ is smaller than 1 and larger than (-1). 


$$
\lambda^{n}=V\left(\lambda_{2}\right)^{n}-(1-V)\left(\lambda_{1}\right)^{n}
$$

Because equation (7) is formed on the basis of the assumption that all phases (filler, matrix and composite) have continuos forms, thermal conductivity of filler seemed to contribute to change to that of composite as much as that of matrix. However, because a step-crosslinking process affects the distribution of HAF particles, thermal conductivity of composite affected appreciably by the biaxial extension occurs during curing process. Therefore, index $(n)$ is replaced by (c.n) and equation (7) becomes:

$$
\lambda^{n}=V\left(\lambda_{2}\right)^{c . n}+(1-V)\left(\lambda_{1}\right)^{n}
$$

where $c$ is a factor of ease in forming conductive chains of filler particles and is smaller than (1) and larger than (0). The more easily filler particles are gathered to form conductive chains, the more thermal conductivity of filler contributes to change to that of composite. Therefore, $c$ becomes closer to (1).

Table (4) shows the calculated values of $\lambda$ according to equation (8) as a function of biaxial extension during the step-crosslinking process. It was found that, $c$ is obviously a linear function of the biaxial extension ratio $k$ of the form, $c=1+a k$, where $a$ is a fitting parameter that has the value of $\approx-0.067$ and $k$ is the biaxial extension ratio.

Table (4): The experimental and calculated $\lambda, \mathrm{w} / \mathrm{mK}$, at different curing state.

\begin{tabular}{c|cc|cc|cc}
\hline \multirow{2}{*}{$\begin{array}{c}\text { Volume } \\
\text { content of }\end{array}$} & \multicolumn{2}{|c|}{ Normal curing } & \multicolumn{2}{|c|}{$30 \%$} & \multicolumn{2}{c}{$60 \%$} \\
HAF, \% & \multicolumn{2}{|c|}{ Theoretical, c= } & \multicolumn{2}{c|}{ Parallel, $c=0.94$} & \multicolumn{2}{c}{ Parallel, $c=0.88$} \\
\hline 0 & 0.151 & 0.151 & 0.151 & 0.151 & 0.151 & 0.151 \\
4.2 & 0.199 & 0.210 & 0.216 & 0.225 & 0.234 & 0.240 \\
11.7 & 0.284 & 0.291 & 0.299 & 0.316 & 0.314 & 0.330 \\
18.1 & 0.357 & 0.339 & 0.368 & 0.361 & 0.381 & 0.380 \\
\hline
\end{tabular}

Moreover, one can follow the above treatment to elucidate the effect of the electron beam dose on the thermal conductivity of the rubber composite. Thermal conductivity of the unloaded sample is highly affected by electron beam dose value, $\mathrm{D}$, and was found to follow the relation;

$$
\lambda_{1}^{\prime}=\lambda_{1}(1+b D)
$$

where $\lambda_{1}$ is the thermal conductivity of the unirradiated one, $b$ is a fitting parameter which has the value $\approx 2.65 \times 10^{-4}$. So, index $(n)$ is replaced by index 
(c.n) and $c$ seems to be independent of the electron beam irradiation dose. Values of $c$ are almost equal unity, but $c$ is smaller in the case of biaxial extension than in the case of electron beam irradiation. Therefore, electron beam irradiation dose affects only the rubber matrix leading to increasing the cross-linking density which inturn increases $\lambda$ and does not affect appreciably the distribution and agglomerations of CB. All experimental data are approximately fitted well with the theoretical value as shown in Tables (4) and (5). Therefore, the modified Agari et al model can explain the experimental data. The effect of radiation on the thermal conductivity of polymers is significantly determined by the irradiation conditions and by the initial degree of crosslinking of the polymer. Studies of radiation effects on $\lambda$ in polymers are mentioned in several publications [39- 42].

Table (5): The experimental and calculated $\lambda$ for normally cured composites at different EB dose.

\begin{tabular}{c|cc|cc|cc|cc}
\hline Volume & \multicolumn{8}{|c}{ Thermal conductivity (w/ mK) } \\
\cline { 2 - 9 } content of & \multicolumn{2}{|c|}{ unirradiated } & \multicolumn{2}{|c}{$500 \mathrm{kGy}$} & \multicolumn{2}{c}{$1000 \mathrm{kGy}$} & \multicolumn{2}{c}{$1500 \mathrm{kGy}$} \\
HAF, \% & Theo. & Exp. & Theo. & Exp. & Theo. & Exp. & Theo. & Exp. \\
\hline 0 & 0.15 & 0.15 & 0.17 & 0.17 & 0.18 & 0.18 & 0.25 & 0.25 \\
4.2 & 0.21 & 0.20 & 0.21 & 0.22 & 0.23 & 0.28 & 0.31 & 0.34 \\
11.7 & 0.29 & 0.28 & 0.30 & 0.30 & 0.32 & 0.34 & 0.38 & 0.40 \\
18.1 & 0.34 & 0.35 & 0.37 & 0.36 & 0.39 & 0.38 & 0.45 & 0.39 \\
\hline
\end{tabular}

\subsection{Composite specific heat:}

The specific heat $(\mathrm{Cp})$ behaviour of irradiated and non-irradiated composites with EB irradiation up to $1500 \mathrm{kGy}$ is shown in Fig. (5). It was noticed that as the dose was increased, $\mathrm{Cp}$ dropped monotonically down. This decrease in specific heat was ascribed to the crosslinking of linear macromolecules, which lowers the number of internal degree of freedom. Moreover, it is interesting to note that the specific heat dropped off with filler content for non-irradiated samples. This decrease can be attributed to the lower specific heat value of CB than NR.

Thermal energy can be considered as a usual damage factor. The effect of heat treatment may be studied by evaluation of changes in specific heat of polymers. The dependence of specific heat on the temperature $\left(30-150^{\circ} \mathrm{C}\right)$ for NR and HAF/ NR composites are presented in Fig. 6 (a- c). It was noticed that the unloaded samples have a lower $\mathrm{Cp}$ than the loaded samples. Furthermore, the measured values of $\mathrm{Cp}$ for these composites (at room temperature) are nearly equally with the change in curing condition at the similar CB loading. Moreover, the unloaded samples have an almost temperature independent behaviour. Meanwhile, it decreases with temperature for all loaded samples. 


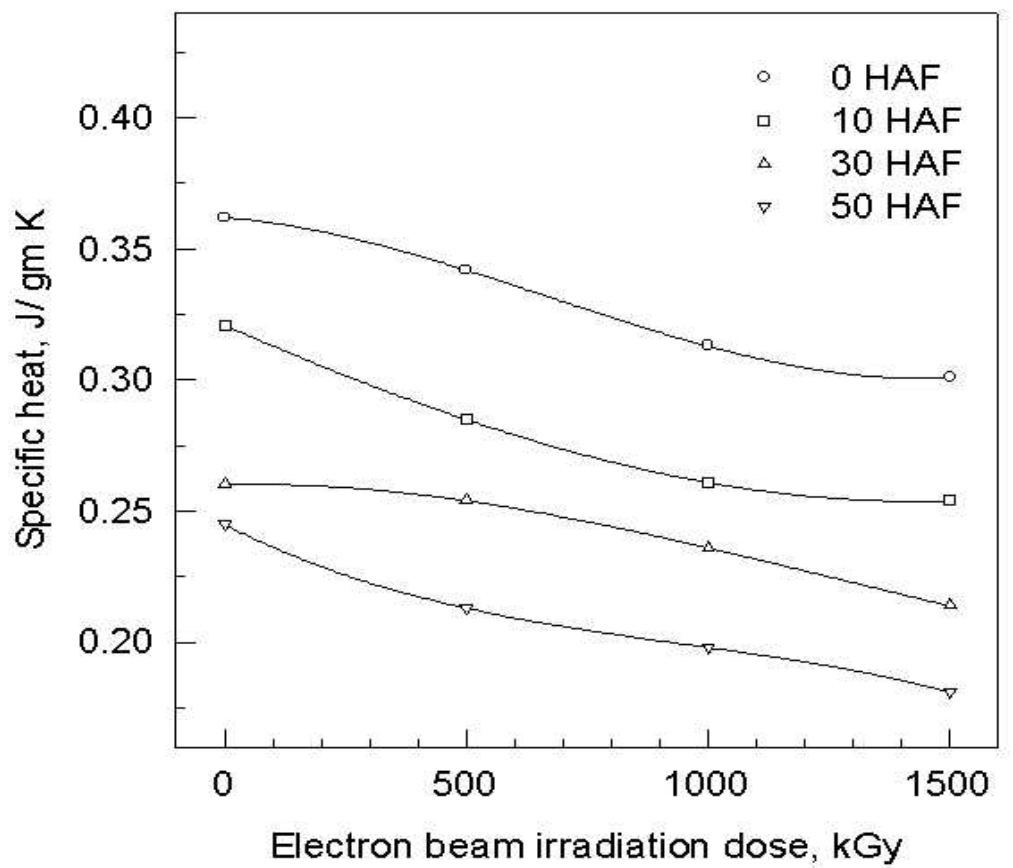

Fig. (5): The specific heat behaviour of HAF / NR normally cured composites with EB irradiation dose.

Table (6) gives the thermal diffusivity values $(\alpha)$ of irradiated HAF/ NR composites at $35^{\circ} \mathrm{C}$, calculated from the previous results. The dependence of $\alpha$ on the absorbed dose is determined mainly by the behaviour of thermal conductivity.

Table (6): The calculated thermal diffusivity $(\alpha)$ at different radiation doses.

\begin{tabular}{l|llll}
\hline Sample & \multicolumn{4}{|c}{$\left.\alpha \mathbf{x ~ 1 0} \mathbf{~ m}^{\mathbf{2}} \mathbf{~ s e c}^{-\mathbf{1}}\right)$} \\
\cline { 2 - 5 } & $\mathbf{0 ~ k G y}$ & $\mathbf{5 0 0} \mathbf{~ k G y}$ & $\mathbf{1 0 0 0} \mathbf{~ k G y}$ & $\mathbf{1 5 0 0} \mathbf{~ k G y}$ \\
\hline 0 HAF & 4.21 & 4.83 & 5.50 & 7.40 \\
10 HAF & 6.72 & 7.42 & 10.35 & 12.17 \\
30 HAF & 11.57 & 12.74 & 13.78 & 16.57 \\
50 HAF & 14.24 & 16.81 & 18.16 & 19.05 \\
\hline
\end{tabular}



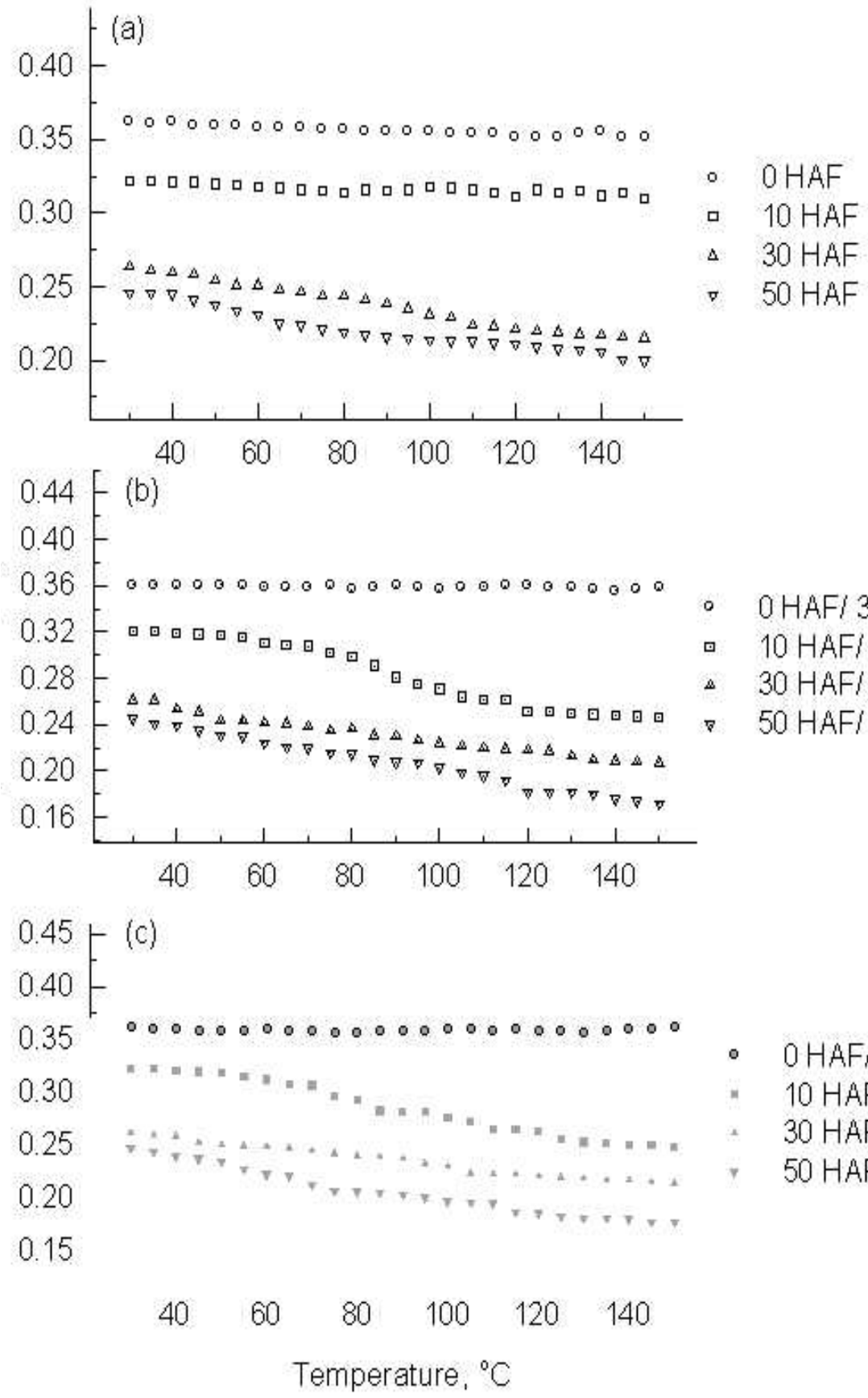

Fig. (6): The dependence of specific heat on the temperature $\left(30-150^{\circ} \mathrm{C}\right)$ for normally cured composites. 


\section{Conclusion:}

The influence of electron beam irradiation and step-crosslinking process on the properties of high abrasion furnace (HAF) carbon black loaded natural rubber vulcanizates have been reported. It was concluded that, the polymer- filler interaction for sample vulcanizated through one stepcrosslinking process is high compared with that vulcanized through the two step- crosslinking processes. The maximum amount of solvent uptake decreased with $\mathrm{CB}$ content and also with irradiation dose while the thermal conductivity value increased, due to the increase of crosslink density. The experimental data for thermal conductivity was in agreement with the calculated one by the modified Agari et al model.

\section{References:}

1. F. Lux, J. Mater. Sci., 28, 285 (1993).

2. R. D. Sherman, L.M. Middleman and S.M. Jacobs, Polym. Eng. Sci., 23, 36 (1983).

3. Kirkpatrik S., Rev. Modern Phys., 45, 574 (1973).

4. J. Meyer, Polym. Eng. Sci., 14, 706 (1974).

5. E.M. Dannenberg, M.E. Jordan and H.M. Cole, J. Polym. Sci., 31, 127 (1958).

6. M. Narkis, A. Ram and Z. Stein, J. Polym. Eng. Sci., 21, 1049 (1981).

7. M. Narkis and A.V. Tobolsky, J. Appl. Polym. Sci., 13, 2257 (1969).

8. M. Narkis and A. Vaxman, J. Appl. Polym. Sci., 29, 1639 (1984).

9. J. Yacubowicz, M. Narkis and L. Benguigui, Polym. Eng. Sci., 30, 459 (1990).

10. F. Bueche, J. Appl. Phys., 44, 532 (1973).

11. K. Miyasaka, K. Watanabe, E. Jojima, H. Aida, M. Sumita and K. Ishikawa, J. Mater. Sci., 17, 1610 (1982).

12. Y.Y. Suzuki, A.J. Heeger and P. Pincus, Macromolecules, 23, 4730 (1990).

13. J.H. Atkins and J.E. Sullivan, Rubber Chem. Technol., 42, 1314 (1969).

14. J.B. Donnet and A. Voet, "Carbon Black", Marcel Dekker, New York (1976) p. 167.

15. Y. Agari and T. Uno, J. Appl. Polym. Sci., 30, 2225 (1985).

16. T. Zaharescu, V. Meltzer, R. Vilcu and D. Opera, J. Thermal Anal., 53, 255 (1998).

17. V. Mentlik, J. Thermal Anal., 39, 1355 (1993).

18. H.J. Flynn, Thermochem. Acta, 217, 129 (1993).

19. A. Tager, "Physical Chemistry of Polymers", Mir Publishers, Moscow, (1978) Ch. 6, p. 149. 
20. D. Hands, Rubber Chem. Technol., 53, 80 (1980).

21. B.A. Briskman, Nucl. Instrum. Meth. In Phys. Resear. (B), 185, 116 (2001).

22. I. Banik and A.K. Bhowmick, Rad. Phys. Chem., 54, 135 (1999).

23. I. Banik and A.K. Bhowmick, Rad. Phys. Chem., 58, 293 (2000).

24. I. Banik, T.K. Bhaki, V.K. Tikky and A.K. Bhowmick, Angew. Makromol. Chem., 263, 5 (1998).

25. I. Banik, A.K. Bhowmick, S.V. Raghavan, A.B. Majali and V.K. Tikky, Polym. Degrad. Stab., 63, 413 (1999).

26. B. Ellis and B.N. Welding, Techniques of Polymer Science (Soc. Chem. Ind. London, 1964) 64.

27. G. Hakvort and L.L. Van Reijen, Thermochem. Acta, 93, 317 (1985).

28. S.D. Gehman, Rubber Chem. Technol., 40, 36 (1967).

29. A.K. Sircar and J.L. Wells, Rubber Chem Technol., 55, 191 (1982).

30. G. Kraus, J. Appl. Polym. Sci., 7, 861 (1963).

31. G. Kraus, Rubber Chem. Technol., 38, 5703 (1965).

32. G. Kraus, editor, "Reinforcement of Elastomers", New York, Wiley, (1965) p. 36.

33. S.E. Gwaily, M.M. Badawy, H.H. Hassan and M. Madani, Poly. Test., 22, 3 (2003).

34. M. Amin, G.M. Nasr, G. Attia and A.S. Gomaa, Mat. Letters, 28, 207 (1996).

35. N.S. Saxena, P. Pradeep, G. Mathew, S.Thomas, M. Gustafsson and S.E. Gustafsson, Europe Poly J., 35, 1687 (1999).

36. T. Sasuga, N. Hayakawa and K. Yoshida, Polymer, 28, 236 (1987).

37. G.J. Morgan and P.D. Scovell, Polym. Lett., 15, 193 (1977).

38. Y. Agari and T. Uno, J. Appl. Polym. Sci., 32, 5703 (1986).

39. R.S. Maxwell, R. Cohenour and W. Sung, Polym. Deg. Stab., 80, 443 (2003).

40. D. Hands, Rubber Chem. Technol., 53, 80 (1980).

41. S.E. Gwaily, M.M. Abdel-Aziz and M. Madani, Polym. Test., 17, 265 (1998).

42. M.M Abdel-Aziz, S.E. Gwaily and M. Madani, Polym. Deg. Stab., 62, 587 (1998). 